\title{
Eccentric Strength Assessment of Hamstring Muscles with New Technologies: a Systematic Review of Current Methods and Clinical Implications
}

João Gustavo Claudino ${ }^{1,2^{*}}$ (D), Carlos Alberto Cardoso Filho ${ }^{1}$ (D) Natália Franco Netto Bittencourt ${ }^{3,4}$ (D), Luiz Gilherme Gonçalves ${ }^{5}$ D, Crislaine Rangel Couto $^{6} \mathbb{B}$, Roberto Chiari Quintão ${ }^{7}$, Guilherme Fialho Reis $^{7}$ (D), Otaviano de Oliveira Júnior ${ }^{7}$ (D), Alberto Carlos Amadio ${ }^{1}$ (D), Daniel Boullosa ${ }^{8,9}$ (iD and Júlio Cerca Serrão ${ }^{1}$ (D)

\begin{abstract}
Background: Given the severe economic and performance implications of hamstring injuries, there are different attempts to identify their risk factors for subsequently developing injury prevention strategies to reduce the risk of these injuries. One of the strategies reported in the scientific literature is the application of interventions with eccentric exercises. To verify the effectiveness of these interventions, different eccentric strength measurements have been used with low-cost devices as alternatives to the widespread used isokinetic dynamometers and the technically limited handheld dynamometers. Therefore, the purpose of the present systematic review was to summarize the findings of the scientific literature related to the evaluation of eccentric strength of hamstring muscles with these new technologies.
\end{abstract}

Methods: Systematic searches through the PubMed, Scopus, and Web of Science databases, from inception up to April 2020, were conducted for peer reviewed articles written in English, reporting eccentric strength of hamstrings assessed by devices, different to isokinetic and handheld dynamometers, in athletes.

Results: Seventeen studies were finally included in the review with 4 different devices used and 18 parameters identified. The pooled sample consisted of 2893 participants (97\% male and 3\% female: $22 \pm 4$ years). The parameters most used were peak force (highest and average), peak torque (average and highest), and betweenlimb imbalance (left-to-right limb ratio). There is inconsistency regarding the association between eccentric hamstrings strength and both injury risk and athletic performance. There is no standardized definition or standardization of the calculation of the used parameters.

(Continued on next page)

\footnotetext{
* Correspondence: claudinojgo@usp.br

${ }^{1}$ School of Physical Education and Sport - Laboratory of Biomechanics,

Universidade de São Paulo, Av. Prof. Mello de Morais, 65 - Cidade

Universitária, São Paulo, São Paulo 05508-030, Brazil

${ }^{2}$ Research and Development Department, LOAD CONTROL, Contagem, Minas

Gerais, Brazil

Full list of author information is available at the end of the article
}

\section{Springer Open}

(c) The Author(s). 2021 Open Access This article is licensed under a Creative Commons Attribution 4.0 International License, which permits use, sharing, adaptation, distribution and reproduction in any medium or format, as long as you give appropriate credit to the original author(s) and the source, provide a link to the Creative Commons licence, and indicate if changes were made. The images or other third party material in this article are included in the article's Creative Commons licence, unless indicated otherwise in a credit line to the material. If material is not included in the article's Creative Commons licence and your intended use is not permitted by statutory regulation or exceeds the permitted use, you will need to obtain permission directly from the copyright holder. To view a copy of this licence, visit http://creativecommons.org/licenses/by/4.0/. 
(Continued from previous page)

Conclusions: The current evidence is insufficient to recommend a practical guide for sports professionals to use these new technologies in their daily routine, due to the need for standardized definitions and calculations.

Furthermore, more studies with female athletes are warranted. Despite these limitations, the eccentric strength of hamstring muscles assessed by different devices may be recommended for monitoring the neuromuscular status of athletes.

Keywords: Knee flexors, Muscle injury, NordBord, Flywheel, Screening, Neuromuscular status, Strain, Athletic performance

\section{Key Points}

- Eccentric hamstrings strength using 4 different devices was evaluated with 18 different parameters after 3-to-6 trials performed unilaterally or bilaterally. Peak force, peak torque, and between-limb imbalance were the most used parameters.

- Eccentric strength hamstring assessed by different devices can be a useful tool for monitoring neuromuscular status of athletes in laboratory and field settings. The assessments should be performed bilaterally with the average of 6 trials.

- There is a need of consensus for identifying the best procedures, definitions, and calculations for evaluation of the eccentric strength of hamstrings in different sport settings.

\section{Background}

Despite the constant evolution of applied sport training tools and technologies, including 24-h monitoring [1] and artificial intelligence [2], hamstring strain injuries are still the most common injuries in sports involving high-speed running activities [3]. A longitudinal analysis between 2001 and 2013 found that hamstring injuries had annually increased by $4 \%$ in professional soccer [4]. In addition to soccer [5], hamstring injuries are common in other team sports as American Football [6], Australian Rules Football [7], basketball [8], cricket [9], rugby [10], and in individual sports as track and field [11].

Eccentric exercises are one of the most popular strategies with strong evidence supporting their use for injury prevention [3]. Given the severe economic and performance implications of hamstring strain injuries, there are attempts to identify the main risk factors associated with these injuries and to develop efficient prevention strategies [3]. In this context, new alternative tools to isokinetic and handheld dynamometers [12, 13], with requirements of minimal equipment and easy-touse in the field, have been developed to verify the effect of eccentric exercises on different eccentric strength measures [14, 15]. Previously, Tous-Fajardo et al. [14] tested an instrumented flywheel leg-curl machine that offered eccentric overload for hamstring development. Opar et al. [15] developed a novel field-testing device, the NordBord, for assessing hamstring eccentric strength, based on the commonly employed Nordic hamstring exercise. These devices have received an increasing interest from practitioners and researchers [16] and many other interesting field applications to reduce hamstring injuries are currently being published [1518].

However, there is no evidence to support the decisionmaking process of practitioners for using these new devices. Therefore, the purpose of the present systematic review was to search, analyze, and summarize the current findings of the scientific literature related to the evaluation of eccentric strength of hamstring muscles with these new technologies.

\section{Methods}

We adopted the Preferred Reporting Items for Systematic Reviews and Meta-Analyses (PRISMA) guidelines [19].

\section{Sources and Study Selection Process}

Three electronic databases (PubMed, Scopus and Web of Science) were systematically searched from inception up to April 2020. The command line ("eccentric strength" OR "Nordic exercise" OR "hamstring”) AND ("equipment" OR "device") was used during the electronic searches. Titles and abstracts were reviewed and screened by the first author (JGC) for the potential eligible studies based on inclusion criteria. Two authors (CACF and NFNB) retrieved and independently assessed the full text of the potential eligible studies. If any doubt arose during this process, a fourth author (JCS) was involved for the final decision by consensus.

\section{Eligibility Criteria}

(1) The study was written in English.

(2) The study was published as original research in a peer-reviewed journal as a full text article.

(3) Data were reported from team or individual sport athletes.

(4) The participants were competitive athletes (defined as Olympic, international, professional, semiprofessional, national, regional, youth academy or division I collegiate); 
(5) Eccentric knee flexors strength was assessed by devices different to isokinetic and handheld dynamometers.

\section{Data Extraction}

Three review authors (JGC, CACF, and NFNB) independently extracted information from the included full-text publications, such as authors, year, population information (mean age, sex ratio, sample size, sport, competitive level), study design, devices used to assess eccentric hamstrings strength, data collection procedures (number of repetitions, performed bilaterally or unilaterally), and the main findings of these studies about injury risk or sports performance. Discrepancies were resolved through discussion until consensus was reached. A narrative synthesis of data was performed.

\section{Quality Assessment}

The quality of all studies was evaluated by two authors (LGG and CRC) using evaluation criteria (Table 1) based on a study by Saw et al. [20]. Scores were allocated based on how well each criterion was met, assuming a maximum possible score of 8 (low risk of bias). Studies with a risk of bias score of 4 or less were considered poor and were subsequently excluded. Once the studies to be included had been defined, we performed an additional review, checking reference lists [21] to identify additional peer reviewed studies that met the inclusion criteria. One study which met inclusion criteria was also included during the peer review process following a reviewer suggestion.

\section{Results}

The initial search returned 1759 articles (see Fig. 1). After the removal of duplicates $(n=563)$, a total of 1196 studies were retained for full text screening. Following the eligibility assessment, 1180 studies were excluded as they did not meet the inclusion criteria. Finally, after considering one study suggested by one of the reviewers, 17 studies were included in this systematic review [14-16, 22-35].

\section{Characteristics of the Studies and Risk of Bias}

The pooled sample size and age included 2893 participants with $22 \pm 4$ years, being composed mostly by male athletes (97\%). The athletes were involved in only seven sports: soccer (70\%), Australian Rules Football (12\%), rugby (7\%), alpine skiing (6\%), cricket (1\%), and track and field (sprinters) (1\%). Three studies did not report the sport of the athletes (3\%). All the studies included had a low risk of bias, with a score $>4$ (see online supplementary Table 1). The average bias score for the studies was 7.6 (range 5-8).

There were 16 observational studies, with 9 crosssectional studies [14, 16, 22, 24-27, 34, 35], 6 prospective cohort studies [23, 28-32] and one reliability and case-control study [15]. The follow-up period of these prospective cohort studies ranged between one preseason period [30] to four seasons [23]. An interventional cross-over study [33] was also included.

\section{Main Findings}

The summary of the 17 studies included in the systematic review is provided in Table 2. Four different devices were found to assess eccentric strength of hamstrings: an instrumented flywheel leg-curl machine (6\%) [14], the NordBord (82\%) [15, 16, 22-24, 26, 28-35], a custommade device based on the prototype validated by Opar et al. [13] with two commercially-available load cells (6\%) [25], and a custom-made device with load cells fixed in the dominant leg with a built-in potentiometer to measure sagittal knee angle (6\%) [27].

The selected studies were related to hamstring $(n=$ $10)$ and anterior cruciate ligament injuries risks $(n=1)$, previous experience effect $(n=1)$, device reliability $(n=$ $1)$, body mass effect $(n=2)$, augmented feedback $(n=$ $1)$, sprint performance $(n=1)$, variability and correlation with isokinetic strength testing $(n=1)$, and body positioning during the test $(n=1)$. In addition, 18 parameters related to eccentric hamstring strength were obtained from the devices using 3-to-6 unilateral or bilateral trials: peak force (average or highest, and absolute or relative), peak torque (average or highest, and absolute or relative), average force $(\mathrm{N})$, average power $(\mathrm{W})$, peak power $(\mathrm{W})$, average velocity $(\mathrm{m} / \mathrm{s})$, peak velocity $(\mathrm{m} / \mathrm{s})$, and between-limb imbalance. The between-limb

Table 1 Risk of bias assessment criteria

\begin{tabular}{|c|c|c|c|c|c|}
\hline \multicolumn{2}{|c|}{ Criteria } & \multirow[t]{2}{*}{ Definition } & \multicolumn{3}{|c|}{ Scoring } \\
\hline & & & 0 & 1 & 2 \\
\hline $\bar{A}$ & Peer reviewed & Study published in peer-reviewed journal & No & Yes & - \\
\hline B & Number of participants & Number of participants included in study findings & $<5$ & $6-30$ & $>31$ \\
\hline C & Population defined & Age, sex, sport, time experience (or level) were described & No & Partly & Yes \\
\hline D & Experimental design & Experimental design of the study period was described and replicable & No & Partly & Yes \\
\hline E & Eccentric strength parameters & The eccentric strength parameters of hamstring assessed by devices were described & No & Yes & - \\
\hline
\end{tabular}




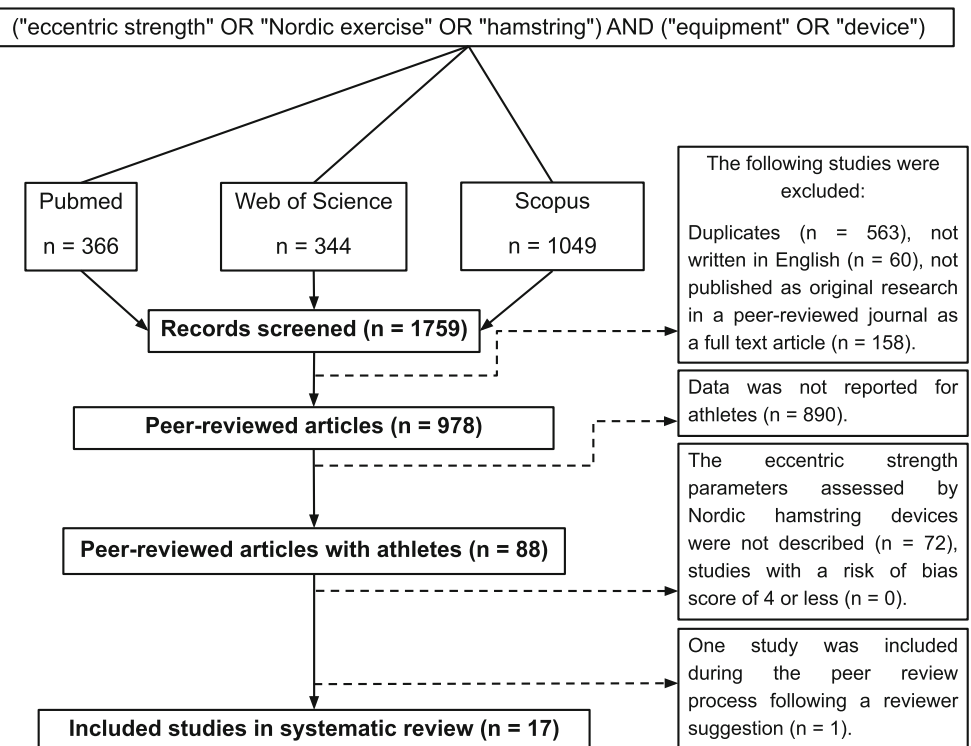

Fig. 1 Study selection PRISMA flow diagram

imbalance included 5 different equations: (1) left-right limb ratio, 2) stronger leg peak force - weaker leg peak force (× 100); (3) 1 - (dominant leg strength/non-dominant leg strength) $\times 100$; (4) stronger limb minus the weaker limb, with the stronger limb being used as the reference value, i.e., 100\%; and (5) (strongest limb weakest limb)/(sum of both limbs)]. However, the same parameters were calculated in different ways in different studies (see details in Table 2).

\section{Discussion}

The purpose of this systematic review was to analyze the findings related to the evaluation of hamstrings eccentric strength with alternative devices. Thus, we described the instruments used to assess eccentric hamstring strength and the clinical outcomes related. There are four different devices used to evaluate eccentric knee flexors strength data. Eccentric hamstring strength using these devices was evaluated from 18 different parameters obtained in 3-6 trials. There is inconsistent evidence correlating eccentric knee flexor strength with an increased risk of sustaining hamstring strain injuries, as well as limited evidence associating eccentric knee flexors strength and sports performance.

The first study found in the literature reported that athletes using an instrumented flywheel leg-curl machine showed greater eccentric strength performances [14]. However, this finding may also suggest an influence of the learning effect $[37,38]$. Therefore, a previous execution of the test procedures to reduce the intra-subject variability, which is called familiarization, is therefore necessary and constitutes an important factor to be considered in this context $[39,40]$. Augmented feedback, with its effects well recognized in the scientific literature [41, 42], was tested in another study using a single session of real-time visual feedback during the Nordic hamstring testing. With this procedure, the mean peak force was increased [33]. Thus, researchers and practitioners should pay attention to the importance of familiarization sessions and whether augmented feedback is being used by athletes, to guarantee higher levels of reliability of the measures obtained with these devices.

The NordBord device $[15,16,22-24,26,28-35]$ and another similar device [25] were the most common instruments used for assessing eccentric hamstring strength. These devices have been developed as low-cost alternatives to the widespread used isokinetic dynamometers [12] and the technically limited handheld dynamometers [13]. The NordBord device for bilateral assessment of Nordic hamstring exercise showed a high to moderate test-retest reliability, i.e., intraclass correlation coefficient $(\mathrm{ICC})=0.83-0.90$ and standard error of measurement $(\mathrm{SEM})=6-9 \%$. However, a lower reliability was found during unilateral testing $(\mathrm{ICC}=0.56-0.73$ and SEM $=10-11 \%$ ) [15]. Also, for between-limb imbalance, it was found that only the ratios based on the peak force averaged across 6 trials had acceptable reliability values $(\mathrm{ICC}=0.85 ; 95 \%$ CI $0.71-0.93 ; \mathrm{SEM}=5 \%, 95 \%$ CI 4-6\%) [15]. Despite the good reliability of some NordBord measures, a poor correlation was found between peak isokinetic hamstring eccentric torque $\left(60^{\circ} / \mathrm{s}\right)$ and forces measured with the NordBord device $\left(r=0.35 ; r^{2}=\right.$ 12\%) [23]. Besides, there was no correlation between bilateral imbalances in isokinetic eccentric contraction strength $(60 \%)$ and eccentric strength measured during the Nordic hamstring exercise [23], despite the former being 
Table 2 Summary of studies

\begin{tabular}{|c|c|c|c|}
\hline Study & Sport (profile) & Experimental design & Main findings \\
\hline $\begin{array}{l}2006 \text { Tous-Fajardo } \\
\text { et al. [14] }\end{array}$ & $\begin{array}{l}\text { Soccer and Rugby } \\
(n=20 ; M) \\
\text { Age: } 26 \pm 4 y \\
\text { Age: } 25 \pm 3 y\end{array}$ & Cross-sectional study & $\begin{array}{l}\text { 1) The flywheel leg-curl device offered eccentric overload } \\
\text { in a range of motion near complete extension about the } \\
\text { knee joint. The magnitude of this overload is related to } \\
\text { the athlete's training background; in other words, the } \\
\text { athletes which had previous experience using this novel } \\
\text { technology showed greater eccentric strength perfor- } \\
\text { mances than novice athletes of the same caliber. It was } \\
\text { observed that biceps femoris muscle plays a more critical } \\
\text { braking role than semitendinosus. }\end{array}$ \\
\hline
\end{tabular}

Device: YoYo (Technology AB, Stockholm, Sweden) instrumented with strain gauge (MuscleLab Force Sensor) to measure the force.

Parameters: peak force (N); average force (N); peak power $(\mathrm{W})$; average power $(\mathrm{W})$; peak velocity $(\mathrm{m} / \mathrm{s})$; average velocity $(\mathrm{m} / \mathrm{s})$. The data was recorded from 6 coupled concentric-eccentric actions. Parameters' definition was not reported (bilateral analysis).

2013 Opar et al. [15]

2015 Bourne et al. [29]
Australian Football, Rugby, Soccer and Sprinting

$(n=50 ; M)$

Age: not reported

Elite and sub-elite
Reliability and casecontrol study

Prospective cohort studies study

$(n=194 ; M)$

Age: $23 \pm 4$ y

Elite, sub-elite, and U19
Australian Football $(n=$ 210; M)
Prospective cohort studies study
2) The experimental device to assess eccentric knee flexor strength showed high to moderate test-retest reliability for measurements when the Nordic hamstring exercise was performed bilaterally $(\mathrm{ICC}=0.83-0.90$ and SEM $=6-9 \%)$, but less reliability during unilateral testing (ICC $=0.56-0.73$ and SEM $=10-11 \%)$. Moreover, between elite athletes who had a unilateral history of hamstring strain injury within the previous 12 months, there was a significant eccentric knee flexor weakness in their injured limb compared to their uninjured limb and to the limbs of uninjured recreational athletes.

Device: a novel device using uniaxial load cells (MLP-1 K; Transducer Techniques, Inc., Temecula, CA; NordBord prototype).

Parameters: peak force (average); the mean of the peak forces from 6 trials of Nordic hamstring exercise in absolute terms (N). Peak force (highest); the best of 6 trials of Nordic hamstring exercise in absolute terms (N), for each limb (left and right). For previously injured players, only the average peak force based on 6 bilateral trials was determined. Between-limb imbalance ratio was measured as the left-right limb ratio. These betweenlimb ratios were them converted to the percentage difference using log-transformed raw data followed by back transformation (bilateral and unilateral analyses).

3) Lower eccentric knee flexor strength was not associated with an increased risk of hamstring strain injury (HSI). But, higher levels of between-limb imbalance $(\geq 15 \%)$ were associated with a significantly increased risk of a subsequent $\mathrm{HSI}$, and this was amplified in athletes who had suffered the same injury in the previous 12 months.

Device: a custom-made uniaxial load cells (Delphi Force Measurement, Gold Coast, Australia; NordBord prototype).

Parameters: peak force (highest); the best of 3 repetitions of Nordic hamstring exercise for each limb (left and right), in absolute terms ( $\mathrm{N}$ ) and relative to body weight $(\mathrm{N} / \mathrm{kg})$.

The between-limb imbalance was calculated as left/right limb ratio, for the uninjured group and as uninjured/injured limb ratio, for the injured group. These betweenlimb ratios were them converted to the percentage difference using log-transformed raw data followed by back transformation. In some analysis, to have a single measure of eccentric hamstring strength for each athlete, an averaging the peak forces from each limb (2-limb-average strength) was made (unilateral and bilateral analysis).

4) Lower limbs that sustained a HSI were weaker than uninjured limbs at the start and end of preseason. 
Table 2 Summary of studies (Continued)

\begin{tabular}{|c|c|c|c|}
\hline Study & Sport (profile) & Experimental design & Main findings \\
\hline & $\begin{array}{l}\text { age: } 23 \pm 4 \\
\text { Elite }\end{array}$ & & $\begin{array}{l}\text { Eccentric hamstring strength below } 256 \mathrm{~N} \text { at the } \\
\text { preseason start and below } 279 \mathrm{~N} \text { at the end of preseason } \\
\text { increases the risk of HSI. The between-limb imbalance in } \\
\text { eccentric hamstring strength was not different between } \\
\text { the injured and uninjured groups. And finally, the inter- } \\
\text { action between athlete age, history of hamstring strain } \\
\text { injury, and eccentric hamstring strength provided better } \\
\text { information on athlete's injury risk profile than only ath- } \\
\text { lete's age and history of HSI. }\end{array}$ \\
\hline
\end{tabular}

Device: a custom-made uniaxial load cells (Delphi Force Measurement, Gold Coast, Australia; NordBord prototype).

Parameters: peak force (average); the mean of the peak forces from 3 trails at Nordic hamstring exercise for each limb (left and right) resulting in a left and right limb measure, reported in absolute terms $(\mathrm{N})$ and relative to body weight $(\mathrm{N} / \mathrm{kg})$. For the athletes that remained injury free, the strength measurement of right and left limb was averaged. The between-limb imbalance was calculated as left/right ratio for uninjured group and as an uninjured/injured limb ratio in the injured group; these between limb ratios were them converted to the percentage difference using log-transformed raw data followed by back transformation (unilateral and bilateral analysis).

2015 Opar et al. [30]

Australian Football

$(n=99 ; \mathrm{M})$

Age: $23 \pm 3$ y

Elite

Prospective cohort study

5) Athletes with a unilateral history of HSI's displayed smaller increases in eccentric hamstring strength compared with the control group athletes, who had no history of injury, during a preseason training. Interestingly, the smaller increase in eccentric strength across the preseason was not restricted to the previously injured limb, as the contralateral limb displayed small increases too, which might suggest that the effects of a prior HSI may be centrally mediated.

Device: a custom-made uniaxial load cells (Delphi Force Measurement, Gold Coast, Australia; NordBord prototype).

Parameters: peak force (average); the mean of the peak forces from 3 contractions during Nordic hamstring exercise for each limb (left and right) in absolute terms (N) and relative to early preseason strength measure expressed as the late preseason/early preseason ratio. In some analysis, to have a single measure of eccentric hamstring strength for each athlete, an averaging the peak forces from each limb (2-limb-average strength) was made (bilateral and unilateral analysis).

6) Eccentric knee flexor strength, as assessed with the NordBord device is largely body mass dependent, but simply dividing eccentric strength by units of BM (i.e., N/ $\mathrm{Kg}$ ) may not be an optimal strategy. To control body mass (BM) effect, practitioners may compare actual test performances with the expected strength for a given BM, using the following predictive equation: eccentric strength $(\mathrm{N})=4 \times \mathrm{BM}(\mathrm{kg})+26.1$. Value deviating from body mass expected values by last $40 \mathrm{~N}(12 \%)$ may be considered greater or lower.

Device: a custom-made uniaxial load cells (Delphi Force Measurement, Gold Coast, Australia; NordBord prototype).

Parameters: peak force (highest); the best of 3 repetitions of Nordic hamstring exercise for right and left limbs expressed in absolute terms $(\mathrm{N})$. In the betweenlimb imbalance, the average strength of left and right legs was used for analysis (bilateral analysis).

2016 Timmins et al. [31]
Soccer

$(n=152 ; \mathrm{M})$

Age: $25 \pm 5 y$
Prospective cohort study

7) Athletes with biceps femoris long head fascicle length (BFIh) shorter than $11 \mathrm{~cm}$ were 4.1 times more likely to suffer a HSI, and low levels of eccentric knee flexor 
Table 2 Summary of studies (Continued) $\mathrm{HSI}$. For every increase in eccentric knee flexor strength, the injury risk was reduced by $9 \%$. No measure of MVIC strength or between-limb imbalances (eccentric strength and BFlh fascicle) led to a statistically increase in HSI risk. Device: a custom-made uniaxial load cells (Delphi Force Measurement, Gold Coast, Australia; NordBord prototype).

Parameters: peak force (average); the mean of the peak forces from 3 contractions during Nordic hamstring exercise for each limb (left and right), reported in absolute terms $(\mathrm{N})$ and relative to body weight $(\mathrm{N} / \mathrm{kg})$. Peak torque (average); the product of peak force (average) by the shank length ( $m$ ) for each limb (left and right), reported in absolute terms ( $\mathrm{Nm}$ ) and relative to body weight $(\mathrm{Nm} / \mathrm{kg})$. The shank length $(\mathrm{m})$ was determined as the distance from the lateral tibial condyle to the mid-point of the brace that was placed around the ankle during Nordic hamstring exercise. Betweenlimb imbalance: calculated as left/right limb ratio, for the uninjured group and as uninjured/injured limb ratio, for the injured group. These between limbs imbalance ratios were them converted to the percentage difference using log transformed was data followed by back transformation. In some analysis, to have a single measure of eccentric knee flexor for each athlete, an averaging the peak forces from each limb (2-limb-average strength) was made (unilateral and bilateral analyses).

2017 van Dyk et al. [32]

Soccer

$(n=413 ; \mathrm{M})$

Age: $26 \pm 5$ y

Elite

2018 Chalker et al.

[33]
Cricket

( $n=44 ; M)$

Age: $18 \pm 2 y$

U23 senior sub-elite and

school level
Prospective cohort study

Interventional cross-over study
8) Eccentric knee flexor strength assessed with the device did not differ between injured and healthy players and do not provide a clinical value in predicting risk of HSI. Muscle strength is part from a multifactorial complex model that may lead to injury.

Device: a custom-made uniaxial load cells (Delphi Force Measurement, Gold Coast, Australia; NordBord prototype).

Parameters: peak force (highest); the best of 3 repetitions of Nordic hamstring exercise for each limb (left and right), reported in absolute terms $(\mathrm{N})$ and relative to body weight (N/kg). Peak force (average); the mean of the peak forces from 3 contractions during Nordic hamstring exercise for each limb (left and right), reported in absolute terms $(\mathrm{N})$ and relative to body weight $(\mathrm{N} / \mathrm{kg})$. Between-limb imbalance was measured as the left-right limb peak force ratio (bilateral and unilateral analyses).

9) The augmented feedback significantly increased mean eccentric knee flexor force, with the majority of this increase occurring in the weaker compared to stronger limb. A single session with the use of real-time visual feedback during the performance of the Nordic hamstring exercise did not improve between limb knee flexor strength asymmetries, but resulted in a non-significant, albeit small to moderate effect size decrease in between limb force asymmetries.

Device: a custom-made uniaxial load cells (Delphi Force Measurement, Gold Coast, Australia; NordBord prototype).

Parameters: peak force (average); the mean of the peak forces from 3 contractions during Nordic hamstring exercise for each limb (left and right), reported in absolute terms (N). Between-limb imbalance; calculated as a left/right limb ratio of the peak force (average), using log transformed raw data followed by back transformation. In some analysis, to have a single measure of eccentric knee flexor for each athlete, an averaging the peak forces from each limb (2-limb-average strength) 
Table 2 Summary of studies (Continued)

\begin{tabular}{|c|c|c|c|}
\hline Study & Sport (profile) & Experimental design & Main findings \\
\hline & & & was made (unilateral and bilateral analysis). \\
\hline 2018 Isik et al. [34] & $\begin{array}{l}\text { Soccer } \\
(n=88 ; M) \\
\text { Age: } 16 \pm 2 \text { y } \\
\text { U19-U14 }\end{array}$ & Cross-sectional study & $\begin{array}{l}\text { 10) The athlete's body weight affects strength } \\
\text { imbalance, and young soccer players with reported } \\
\text { lower extremity injuries in the previous } 2 \text { years had } \\
\text { similar eccentric hamstring strength imbalance in } \\
\text { comparison to non-injured soccer players. } \\
\text { Device: NordBord Hamstring Testing device } \\
\text { (Qutbluebox, Queensland, AUS). } \\
\text { Parameter: between-limb imbalance; calculated as stron- } \\
\text { ger leg peak force (N) - weaker leg peak force (N), with } \\
\text { each leg force data being obtained from the best of } 3 \\
\text { repetitions of Nordic hamstring exercise for each limb } \\
\text { (left and right), reported in absolute terms (N) (unilateral } \\
\text { analysis). }\end{array}$ \\
\hline
\end{tabular}

2018 van Dyk et al. [23]

Soccer

$(n=288 ; M)$

Age: $25 \pm 5 y$

Elite
Prospective cohort study

11) There was a substantial variability for isokinetic measures between seasons, as demonstrated by the large measurement error for all the contraction modes. A poor correlation was found between peak isokinetic hamstring eccentric torque and peak eccentric knee strength measured during Nordic hamstring exercise. Also, no correlation between bilateral imbalances measured in isokinetic strength testing and Nordic hamstring exercise testing was found.

Device: a custom-made uniaxial load cells (Delphi Force Measurement, Gold Coast, Australia; NordBord prototype).

Parameter: peak force (highest); the highest value obtained from 3 repetitions for each limb (left and right) in absolute terms (N), resulting in a left and right limb measure. Peak force (average); the mean of the peak forces from 3 contractions during Nordic hamstring exercise for each limb (left and right), reported in absolute terms (N). The peak force (highest) from Nordic hamstring exercise was correlated to the peak torque of isokinetic eccentric contraction at $60^{\circ} / \mathrm{s}\left(r=0.35 ; r^{2}=\right.$

12\%). The between-limb imbalance was calculated as a percentage following the formula left/right limb ratio of peak force.

12) There is a description of maximal eccentric hamstrings strength in alpine skiers from the youth to the elite level. This study highlights the importance of biological maturation regarding maximal eccentric hamstrings strength values in youth athletes, more specifically those who are close to their growth spurts. This study presents novel data that may offer novel insights for anterior cruciate ligament injury prevention in Alpine Skiing.

Device: NordBord Hamstring Testing device (Vald Performance, Newstead, Australia).

Parameter: all participants performed one set of 3 repetitions with $5-10 \mathrm{~s}$ of rest between repetitions. The peak force was considered the maximum value between the 3 repetitions, for the left and the right limb. The limbs' asymmetry during testing was calculated as the difference between stronger and weaker leg expressed as a percentage. The parameters analyzed were both right and left limbs as well as limbs asymmetry.

13) During Nordic hamstring exercise with hip flexed in $90^{\circ}$, there were higher eccentric knee flexor torque and lower hamstring EMG (biceps femoral long head and semitendinosus) levels compared to Nordic hamstring exercise with hip in neutral position in most phases of movement. There was similar peak eccentric knee flexor torque and EMG levels in Nordic hamstring exercise performed unilateral and bilateral modes, independently of hip position. During Nordic hamstring exercise with 
Table 2 Summary of studies (Continued)

Study Sport (profile)

\section{Main findings}

hip in neutral position, there was higher semitendinosus activity during the movement's early phase and lower during movement's final phase (toward full knee extension) than biceps femoral long head activity. During Nordic hamstring, exercise with hip flexed in $90^{\circ}$, there was higher semitendinosus activity than biceps femoral long head activity in the second half of bilateral movement and in the final phase of unilateral movement.

Device: a device with load cells (ELAF, $1250 \mathrm{~N}$; TE Connectivity, Schaffhausen, Switzerland) and a potentiometer (P4500; Novotechnik, Ostfildern, Germany). Parameter: peak torque (average); mean of instantaneous force in the dominant leg $(\mathrm{N})$ multiplied by the lever arm (distance between femur's lateral epicondyle and the center of the load cells) in meters, recorded in two repetitions.

2020 Giakoumis et al. [26]
Elite
Age: 19-33 y
Cross-sectional study
14) Male athletes produced greater absolute force levels compared to female athletes, but relative force (normalized to body weight) was similar between sexes. Long sprinters $(400 \mathrm{~m})$ presented stronger right leg than left leg, and short sprinters $(100 \mathrm{~m} / 200 \mathrm{~m} / 110 \mathrm{~m})$ showed similar strength between legs. There were no differences in eccentric hamstring strength between previously injured and uninjured athletes.

Device: NordBord Hamstring Testing device

(Qutbluebox, Queensland, AUS).

Parameter: peak force (highest); the highest value obtained from 3 repetitions for each limb (left and right) in absolute terms $(\mathrm{N})$ and relative to bodyweight $(\mathrm{N} / \mathrm{kg})$, resulting in a left and right limb measure. Peak force (average); the mean of the peak forces from 3 contractions during Nordic hamstring exercise for each limb (left and right), reported in absolute terms (N) and relative to bodyweight $(\mathrm{N} / \mathrm{kg})$. Peak torque (highest) $(\mathrm{Nm})$; calculated by multiplying the length of the shank by the peak force (highest), reported in absolute terms $(\mathrm{Nm})$ and relative to body weight $(\mathrm{Nm} / \mathrm{kg})$. The shank length $(\mathrm{m})$ was determined as the distance from the lateral tibial condyle to the mid-point of the brace that was placed around the ankle during Nordic hamstring exercise. Between-limb imbalance: calculated by dividing torque or force of right limb by the measures of left limb. $0 \%$ indicates no imbalance, imbalance $>0 \%$ indicates more force/torque on the right side (unilateral and bilateral analysis)

15) The absolute and relative Nordic hamstring strength increases with players' age, but this increase was not linear and there was an abrupt increase in Nordic hamstring strength in U16 category. In general, the body size is largely responsible for the observed age-related increase in absolute Nordic hamstring strength. Bilateral Nordic hamstring strength asymmetry varied nonsignificant (8-16\%) between age groups, with the highest asymmetries being observed in U12 and U13 age groups (>15\%).

There was a large negative correlation between eccentric knee flexor strength and sprint performance, with $27 \%$ spring performance variance being explained by relative Nordic hamstring strength $(\mathrm{Nm} / \mathrm{kg})$.

Device: a custom-made uniaxial load cells (FL34-100 kg; Forsentek Co., Shenzhen, China; NordBord prototype). Parameter: peak force (highest): the highest value obtained from 3 repetitions for each limb (left and right) in absolute terms $(\mathrm{N})$ and relative to bodyweight $(\mathrm{N} / \mathrm{kg})$, resulting in a left and right limb measure. Peak torque (highest): the product of peak force by the shank length 
Table 2 Summary of studies (Continued)

Study Sport (profile)

Experimental design

2020 Ribeiro-Alvares

et al. [25]
Soccer

( $n=210 ; M)$

Age: $24 \pm 5 y$

Elite

Cross-sectional study

Cross-sectional study

$(n=284 ; M)$

Age: $23 \pm 4 y$

Regional

\section{Main findings}

$(\mathrm{m})$, left and right, in absolute terms $(\mathrm{Nm})$ and relative to body weight $(\mathrm{Nm} / \mathrm{kg})$. The shank length $(\mathrm{m})$ was determined as the distance from the lateral tibial condyle to the mid-point of the brace that was placed around the ankle during Nordic hamstring exercise. The bilateral strength asymmetry of knee eccentric flexor strength was expressed in \% following the formula: 1 - (dominant leg strength/non-dominant leg strength) $\times 100$. In some analysis, to have a single measure of eccentric knee flexor for each athlete, an averaging the peak forces or peak torque from each limb (2-limb-average strength) was made (unilateral and bilateral analysis).

16) Previously injured players presented strength deficit on injured limb in relation to their contralateral limb and to the uninjured player's limb. Previously injured and uninjured players displayed similar between-limb asymmetry values, but half of the previously injured players and $37 \%$ of uninjured players presented between limb strength asymmetry $>10 \%$.

Device: device was based on the prototype validated by Opar et al. (2013) with two independent commercially available load cells (Elastic, E-sporte Soluções Esportivas, Brasilia, Brazil).

Parameter: peak force (highest); the highest value obtained from 3 repetitions for each limb (left and right) in absolute terms $(\mathrm{N})$, resulting in a left and right limb measure. Between-limb imbalance: calculated as the player's stronger limb minus the weaker limb with the stronger limb being used as the reference value (i.e., $100 \%$ ). For the injured group, limbs were analyzed separately; for the control group, the eccentric knee flexor peak force was average between limbs (bilateral and unilateral analyses).

17) Athlete's age was negative associated with preseason eccentric hamstring strength with a mean reduction on knee flexor strength of $0.9 \%$ per year increased. Players with previous hamstring injury duration of more than 3 weeks had 9\% lower preseason knee flexor eccentric strength compared to players with no previous hamstring injury.

Device: a custom-made uniaxial load cells (Delphi Force Measurement, Gold Coast, Australia; NordBord prototype).

Parameter: peak force (average); the mean of the peak forces from 3 contractions during Nordic hamstring exercise for each limb (left and right), reported in relative terms (N/kg). Between-limb imbalance: analyzed using the formula: (strongest limb - weakest limb)/(sum of both limbs) (bilateral and unilateral analyses).

\footnotetext{
Cross-sectional: consist in assessing a population at a single point in time, cannot demonstrate temporality, therefore can present prevalence and associated factors [36]

Interventional cross-over study: interventional study where participants underwent for all treatment's arms

Prospective cohort study: it is suggested to be the gold standard of observational research and can identify the potential risk factors for an injury or disease, due to the temporality [36]

Reliability and case-control study: in a reliability study design, researchers are interested in measuring the consistency of some measure across time, the consistency of people's responses on a measure, and the consistency of different observers and their judgments of some measures. Case-control study designs refers to retrospective observational study in which participants are identified and selected based on their case status (i.e., injured or not injured); this type of study allows the establishment of a statistical association between the exposure for some variables and outcomes [36]

$n$ number of subjects, $F$ female, $M$ male, $y$ years old, $N$ Newton, $B M$ body mass, Kg kilogram, $H S I$ hamstring strain injury, ICC intraclass correlation coefficient, SEM standard error of measurement
}

considered the gold standard [43] and its use to determine quadriceps-to-hamstring ratios aiming to identify risk profiles [44]. The authors also reported a substantial variability for isokinetic measures between different seasons with the SEM ranging 15-19\% [23]. Additionally, during the Nordic hamstring exercise with the hip in neutral position, there was a higher semitendinosus activity in the early phase of the movement and a higher biceps femoral long head activity during the final phase. This behavior was changed with hip flexed at $90^{\circ}$, where a higher semitendinosus activity 
was found in the final phase of the movement [27]. During the Nordic hamstring exercise, the athlete is required to resist via forceful eccentric knee flexor contractions, thus increasing the external torque around the knee joint as the athlete progresses toward the ground. In contrast, isokinetic testing imposes maximal effort throughout the full range of motion [28]. The poor correlation of imbalance measures between both tests may be justified by the fact that the Nordic hamstring exercise only measures the imbalance when both legs are tested at the same time [45]. In contrast, during isokinetic testing, each leg is evaluated separately. Therefore, bilateral testing should be preferred when evaluating the Nordic hamstring exercise with these devices.

It has been previously suggested that athletes with a history of hamstring injuries present knee flexor weakness in their injured limb when compared to their uninjured limb and to uninjured athletes $[15,25]$. In the same manner, players with hamstring injury lasting more than 3 weeks, exhibited a 9\% lower knee flexor eccentric strength than uninjured players during the preseason [24]. Contrary to this, it has been also observed no difference in eccentric hamstring strength between previously injured and uninjured athletes [26]. Furthermore, previously hamstring injured and uninjured athletes have displayed similar between-limb asymmetries on eccentric knee flexors strength, with half of the previously injured athletes and $37 \%$ of the uninjured athletes presenting between-limb asymmetries above $\sim 10 \%$ [25]. In this regard, players with previous lower extremity injuries had shown similar eccentric strength imbalances in comparison to non-injured players, with athletes' body masses being positively correlated to bilateral eccentric strength imbalances [34]. This conflicting evidence was also found in prospective cohort studies. Previously, some authors have suggested that levels of eccentric knee flexors strength below $256 \mathrm{~N}$ at the start of pre-season, $279 \mathrm{~N}$ at the end of pre-season in Australian Rules footballers [28], and $337 \mathrm{~N}$ for the whole season in soccer players [31] may increase the risk of a hamstring strain injury by $\sim 4.4$ times [31]. Furthermore, higher levels of between-limb imbalance $(>15 \%)$ were also associated with an increased risk of hamstring strain injury [29]. Conversely, others did not find any association between eccentric hamstring strength or between-limb imbalances and an increased risk of hamstring strain injuries $[28,29,31,32]$. However, it is noteworthy that these previous studies evaluated players from different sports. Therefore, it is possible that the differences between physical characteristics of these athletes $[46,47]$ and the specific demands of each sport could explain the inconsistencies observed in these previous studies [29, 48, 49]. Moreover, these previous studies looked for this association in a linear fashion while isolating specific parameters. Since hamstring injuries have a multifactorial nature, it may be suggested for future studies to better test this association through the combination of different risk factors, including sports performance, running demands, and hamstrings strength [50].

Another reason for the inconsistencies observed in previous literature could be the different characteristics between hamstring demands during running activities and the Nordic hamstring exercise. Although the exact mechanisms for hamstring injuries are not fully understood [50,51], it is suggested to occur mainly during the late swing phase or the early stance phase, in which hamstrings are highly activated at longer lengths [5155]. Hamstrings are required to contract eccentrically during the terminal swing phase of a running gait cycle to decelerate the forward swinging shank and to oppose the external hip-flexor and knee extensor torques developed [56-58]. In addition, they are required to contract concentrically during early stance to absorb the high ground reaction forces [59]. Further, hamstrings demands increase with higher running speeds, such as sprinting at maximal or close to maximal speeds [54, 59, 60], which is the situation at which the hamstrings strain injuries frequently occur [53, 61]. However, eccentric hamstring strength assessment with these devices occurs at the slowest possible knee angular velocity $[15,31]$, with trials performed at very low angular velocities of $30^{\circ} \mathrm{s}^{-1}$ [62]. Furthermore, it has been also shown that when running at $\sim 75 \%$ of the maximal running speed, there was approximately a $15 \%$ higher hamstrings electromyographic (EMG) activity than during a maximum voluntary isometric contraction [63] and higher EMG amplitudes when compared to the Nordic hamstring exercise [63, 64]. Therefore, the strength measures assessed during the Nordic hamstring exercise do not elicit the same demands as during running activities. In addition, some evidence have pointed out that low levels of eccentric strength may reduce the hamstring ability to perform well during the gait cycle, potentially increasing the hamstring strain injury risk [52,65]. While we are not questioning the well-established effects of the Nordic hamstring exercise on reducing hamstring strain injury risk [66-69], it is important to consider that hamstring strain injuries are multifactorial and complex [51, 70-72], and therefore, caution should be taken by practitioners when using some isolated measurements, such as peak forces or between-limb imbalances during this test in an attempt to estimate a hamstring strain injury risk.

The horizontal component of the ground reaction forces is suggested to be the key mechanical feature of sprint acceleration performance [73-77], with subjects who are able to produce the greatest amounts of horizontal force in sprint running presenting higher eccentric hamstring peak torque capability and also being able to activate to a greater extent their hamstring muscles 
before initial ground contact [75]. Of note, this parameter can be monitored with other new technologies not included in the current review (i.e., mobile app and sports radar system) [77, 78]. In addition, the contributions of horizontal and vertical components of ground reaction forces on sprint performance have been described in the literature to be $17-61 \%$ and $17-23 \%$, respectively $[73,76,79,80]$. In this regard, limited evidence indicated that eccentric hamstring strength measured with the NordBord device was largely correlated to 20-m sprint performance $\left(r=-0.52 ; r^{2}=27 \%\right.$, $p<0.05)$ [22]. Therefore, all this information suggests that higher levels of eccentric hamstring strength could be an important component of an athlete's neuromuscular capabilities to achieve higher speeds and thus a better sprint performance $[22,75]$. Notably, the $20-\mathrm{m}$ sprint time and the eccentric hamstring strength measured in the Nordic hamstring exercise share a common variance of $27 \%$ in youth soccer players [22]. Thus, sports practitioners interested in monitoring the neuromuscular status during the training process could use these tools to evaluate the eccentric strength of hamstring muscles in the same manner as vertical jump evaluations. This suggestion is based on the association levels observed between sprint performances and vertical jump height in elite sprinters $\left(r^{2}=47\right.$ to $\left.76 \%\right)$ [81], collegiate soccer players $\left(r^{2}=22\right.$ to $\left.46 \%\right)$ [82], and elite young basketball players $\left(r^{2}=37 \%\right)$ [83]. Therefore, these devices may serve as an appealing option for neuromuscular status monitoring, as occurs with vertical jump performance evaluations [84].

Attention should be given to how the eccentric hamstring strength parameters evaluated by these devices were calculated in the articles included. In an instrumented flywheel leg-curl device, the parameters were calculated from 6 coupled concentric-eccentric actions [14]. During Nordic hamstring exercises, some studies adopted the peak force averaged from 3 [23, 24, 26, 2833] or 6 [15] bilateral maximal repetitions in absolute values $(\mathrm{N})[15,23,26,28-33]$, while others reported these values normalized by body mass $(\mathrm{N} / \mathrm{kg})[24,26,28$, $31,32]$. There were also reports on these values relative to moment of the season, expressed as the late preseason/early preseason ratio [30]. Some researchers used the highest peak force of 3 repetitions in absolute values (N) $[16,22,23,25,26,29,32,35]$ or normalized by body mass $[22,26,29,32]$, while others adopted the highest peak force of 6 repetitions in absolute terms (N) [15]. Some authors measured eccentric hamstring torque through the product of mean peak force data $(\mathrm{N})$ [27, $31]$ or the highest peak force data $(\mathrm{N})[22,26]$ by the lever arm of shank length, with this measure reported in absolute terms $(\mathrm{Nm})[22,26,27,31]$ or normalized by body mass $(\mathrm{Nm} / \mathrm{kg}) \quad[22, \quad 26,31]$. All these inconsistencies were also presented for between-limb imbalance measures, calculated as percentage differences of left/right limb force ratio for uninjured players and uninjured/injured limbs force ratio in the injured group $[28,29,31]$. In other studies, it was calculated as the left-right limb force ratio [32], converted to the percentage difference using log-transformed raw data followed by back transformation $[15,33]$, as the stronger leg peak force minus weaker leg $[25,34,35]$, as the stronger limb being used as the reference value (i.e., 100\%) [25], or by dividing torque or force of the right limb by the measures of left limb [26]. There was also one study that calculated Eq. 1 [24]:

(strongest limb - weakest limb)/sum of both limbs

and another that adopted Eq. 2 [22]:

(dominant leg strength/non-dominant leg strength) $* 100$

All this variety makes it difficult to compare the different results observed in studies examining lower limbs imbalance with regard to hamstring strain injury or sports performance.

Lastly, although with a limited number of athletes for sex comparisons, male athletes were found to produce greater absolute force levels compared to female athletes, but the relative force (normalized to body mass) was similar between sexes [26]. This is important as eccentric hamstring strength assessed by these devices is suggested to be body mass dependent [16, 22]. Additionally, Nordic hamstring strength increases with the player's age, and body size has been reported to be largely related to the increase in absolute Nordic hamstring strength [22]. Therefore, adopting absolute units (i.e., N and $\mathrm{Nm}$ ) or simply dividing eccentric hamstring strength by body mass (i.e., $\mathrm{N} / \mathrm{Kg} ; \mathrm{Nm} / \mathrm{kg}$ ) may not be optimal strategies. In this regard, future studies may use allometric scaling for solving this issue. An alternative method could be to apply a correction factor, as previously suggested [16] with the following Eq. (3):

$$
\text { eccentric strength }(\mathrm{N})=4 * \text { body mass }(\mathrm{kg})+26.1
$$

Finally, it is worth noting that in the first studies found in the scientific literature, 6 repetitions were performed for the hamstring assessments [14, 15]. Among these studies, in a single reliability study, the authors reported that, when peak force was averaged across the 6 trials, the results were more reliable [15]. This finding agrees with previous studies that verified greater sensitivity for the averaged results than for the highest performance in 
trials for detecting trained related changes in countermovement jumps [84, 85]. Future studies should consider a standard method to assess eccentric knee flexors strength during the Nordic hamstring exercise, including 6 trials and body mass normalization. On the other hand, from a clinical perspective, these measures should be used over the season thus allowing the management of training loads and also as criteria before returning to play. This information could guide sports professionals during the training and rehabilitation processes to decrease injury and re-injury risks.

\section{Conclusions}

There is a growing scientific evidence suggesting the use of new devices to evaluate the eccentric hamstring strength of athletes. These devices have been developed as low-cost alternatives to the widespread used isokinetic dynamometers and the technically limited handheld dynamometers. There is inconsistent evidence correlating eccentric knee flexor strength with an increased injury risk of hamstrings, and very limited evidence about its relationship with athletic performance. The parameters most widely used during these evaluations were peak force (average or highest), peak torque (average or highest), and between-limb imbalance (left-right limb ratio). Due to the variety of strength measurements observed in the current literature, there is an urgent need for better defining the procedures and the parameters to be used with these devices. The eccentric strength of hamstrings assessed by these devices may be useful as a tool for monitoring the neuromuscular status of athletes during a whole season.

\section{Supplementary Information}

The online version contains supplementary material available at https://doi. org/10.1186/s40798-021-00298-7.

Additional file 1.

\section{Abbreviations \\ BM: Body mass; EMG: Electromyography; F: Female; HSI: Hamstring strain injury; ICC: Intraclass correlation coefficient; M: Male; $n$ : Sample size; PRIS MA: Preferred Reporting Items for Systematic Reviews and Meta-Analyses; $r^{2}$ : Coefficient of determination; SEM: Standard error of measurement; y: Years old}

\section{Acknowledgements}

We would like to thank for the authors of cited articles who collaborated to obtain the data.

\section{Authors' Contributions}

JGC: design, collection, analysis, interpretation of data, and writing up of the paper. CACF: design, collection, analysis, interpretation of data, and writing up of the paper. NFNB: design, collection, analysis, interpretation of data, and writing up of the paper. LGG: interpretation of data and writing up of the paper. CRC: design, collection, analysis, interpretation of data, and writing up of the paper. RCQ: interpretation of data and writing up of the paper. GFR: interpretation of data and writing up of the paper. OOJ: design, interpretation of data, and writing up of the paper: ACMP: interpretation of data and writing up of the paper. DB: interpretation of data and writing up of the paper. JCS: design, collection, analysis, interpretation of data and writing up of the paper. The author(s) read and approved the final manuscript.

\section{Funding}

No sources of funding were used to assist in the design, collection, analysis, and interpretation of data or in writing of this manuscript.

\section{Availability of Data and Materials}

After publication, all data necessary to understand and assess the conclusions of the manuscript are available to any reader of Sports Medicine-Open.

Ethics Approval and Consent to Participate

Not applicable.

\section{Consent for Publication}

All authors consent to the publication of the manuscript.

\section{Competing Interests}

João Gustavo Claudino, Carlos Alberto Cardoso Filho, Natália Franco Netto Bittencourt, Luiz Guilherme Gonçalves, Crislaine Rangel Couto, Roberto Chiari Quintão, Guilherme Fialho Reis, Otaviano de Oliveira Júnior, Alberto Carlos Amadio, Daniel Boullosa, and Júlio Cerca Serrão declare that they have no conflicts of interest relevant to the content of this review.

\section{Author details}

${ }^{1}$ School of Physical Education and Sport - Laboratory of Biomechanics, Universidade de São Paulo, Av. Prof. Mello de Morais, 65 - Cidade Universitária, São Paulo, São Paulo 05508-030, Brazil. ²Research and Development Department, LOAD CONTROL, Contagem, Minas Gerais, Brazil. ${ }^{3}$ Uni-BH University Center - Physical Therapy Department, Belo Horizonte, Minas Gerais, Brazil. ${ }^{4}$ PHAST, Belo Horizonte, Minas Gerais, Brazil. ${ }^{5}$ Physiology Department, Botafogo Futebol Clube, Ribeirão Preto, São Paulo, Brazil.

${ }^{6}$ Universidade Federal de Minas Gerais, Belo Horizonte, Minas Gerais, Brazil. ${ }^{7}$ Medical Department, Clube Atlético Mineiro, Belo Horizonte, Minas Gerais, Brazil. ${ }^{8}$ Sport and Exercise Science, College of Healthcare Sciences, James Cook University, Townsville, QLD, Australia. ${ }^{9}$ Graduate Program in Movement Sciences, INISA, Universidade Federal de Mato Grosso do Sul, Campo Grande, Mato Grosso do Sul, Brazil.

Received: 16 July 2020 Accepted: 3 January 2021

Published online: 28 January 2021

\section{References}

1. Duking P, Achtzehn S, Holmberg H-CC, Sperlich B, Dueking P, Achtzehn S, et al. Integrated framework of load monitoring by a combination of smartphone applications, wearables and point-of-care testing provides feedback that allows individual responsive adjustments to activities of daily living. Sensors. 2018;18:1-11.

2. Claudino JG, de Oliveira Capanema D, de Souza TV, Serrão JC, Machado Pereira AC, Nassis GP. Current approaches to the use of artificial intelligence for injury risk assessment and performance prediction in team sports: a systematic review. Sport Med Open. 2019;5(1):28.

3. Shield AJ, Bourne MN. Hamstring injury prevention practices in elite sport: evidence for eccentric strength vs. lumbo-pelvic training. Sport Med. 2018; 48:513-24.

4. Ekstrand J, Waldén M, Hägglund M. Hamstring injuries have increased by $4 \%$ annually in men's professional football, since 2001: a 13-year longitudinal analysis of the UEFA Elite Club injury study. Br J Sports Med. 2016;50:731-7.

5. van Dyk N, Faroog A, Bahr R, Witvrouw E. Hamstring and ankle flexibility deficits are weak risk factors for hamstring injury in professional soccer players: a prospective cohort study of 438 players including 78 injuries. Am J Sports Med. 2018:46:2203-10.

6. Werner BC, Belkin NS, Kennelly S, Weiss L, Barnes RP, Potter HG, et al. Acute gastrocnemius-soleus complex injuries in national football league athletes. Orthop J Sport Med. 2017;5:1-6.

7. Watsford ML, Murphy AJ, McLachlan KA, Bryant AL, Cameron ML, Crossley $\mathrm{KM}$, et al. A prospective study of the relationship between lower body 
stiffness and hamstring injury in professional Australian rules footballers. Am J Sports Med. 2010;38:2058-64.

8. Drakos MC, Domb B, Starkey C, Callahan L, Allen AA. Injury in the National Basketball Association: a 17-year overview. Sports Health. 2010;2:284-90.

9. Orchard JW, Kountouris A, Sims K. Risk factors for hamstring injuries in Australian male professional cricket players. J Sport Health Sci. 2017;6:271-4.

10. Whitehouse T, Orr R, Fitzgerald E, Harries S, McLellan CP. The epidemiology of injuries in Australian Professional Rugby Union 2014 Super Rugby Competition. Orthop J Sport Med. 2016;4:1-10

11. Sugiura Y, Sakuma K, Sakuraba K, Sato Y. Prevention of hamstring injuries in collegiate sprinters. Orthop J Sport Med. 2017;5:1-6.

12. Aagaard P, Simonsen EB, Magnusson SP, Larsson B, Dyhre-Poulsen P. A new concept for isokinetic hamstring: quadriceps muscle strength ratio. Am J Sports Med. 1998;26:231-7.

13. Whiteley R, Jacobsen P, Prior S, Skazalski C, Otten R, Johnson A. Correlation of isokinetic and novel hand-held dynamometry measures of knee flexion and extension strength testing. J Sci Med Sport. 2012;15:444-50.

14. Tous-Fajardo J, Maldonado RA, Quintana JM, Pozzo M, Tesch PA. The flywheel leg-curl machine: offering eccentric overload for hamstring development. Int J Sports Physiol Perform. 2006;1:293-8.

15. Opar DA, Piatkowski T, Williams MD, Shield AJ. A novel device using the Nordic hamstring exercise to assess eccentric knee flexor strength: a reliability and retrospective injury study. J Orthop Sports Phys Ther. 2013;43: $636-40$

16. Buchheit M, Cholley Y, Nagel M, Poulos N. The effect of body mass on eccentric knee-flexor strength assessed with an instrumented Nordic hamstring device (Nordbord) in football players. Int I Sports Physiol Perform. 2016;11:721-6.

17. Macdonald B. An investigation into the immediate effects of pelvic taping on hamstring eccentric force in an elite male sprinter - a case report. Phys Ther Sport. 2017;28:15-22.

18. Wik EH, Auliffe SM, Read PJ. Examination of physical characteristics and positional differences in professional soccer players in Qatar. Sports. 2018; 7(1):9.

19. Moher D, Liberati A, Tetzlaff J, Altman DG. Preferred reporting items for systematic reviews and meta-analyses: the PRISMA statement. PLoS Med. 2009;6:e1000097.

20. Saw AE, Main LC, Gastin PB. Monitoring the athlete training response: subjective self-reported measures trump commonly used objective measures: a systematic review. Br J Sports Med. 2016;50:281-91.

21. Horsley T, Dingwall O, Sampson M. Checking reference lists to find additional studies for systematic reviews. Cochrane Database Syst Rev. 2011; (8):MR000026. https://doi.org/10.1002/14651858.MR000026.pub2. Accessed 10 Jan 2021.

22. Markovic G, Sarabon N, Boban F, Zoric I, Jelcic M, Sos K, et al. Nordic hamstring strength of highly trained youth football players and its relation to sprint performance. J Strength Cond Res. 2020;34:800-7.

23. van Dyk N, Witvrouw E, Bahr R. Interseason variability in isokinetic strength and poor correlation with Nordic hamstring eccentric strength in football players. Scand J Med Sci Sports. 2018;28:1878-87.

24. Vicens-Bordas J, Esteve E, Fort-Vanmeerhaeghe A, Bandholm T, Clausen MB, Opar DA, et al. Eccentric hamstring strength is associated with age and duration of previous season hamstring injury in male soccer players. Int J Sports Phys Ther. 2020;15:246-53.

25. Ribeiro-Alvares JB, Oliveira GDS, De Lima-E-Silva FX, Baroni BM. Eccentric knee flexor strength of professional football players with and without hamstring injury in the prior season. Eur J Sport Sci. 2020;1-9. https://doi. org/10.1080/17461391.2020.1743766 [published online ahead of print, 2020 Mar 26].

26. Giakoumis M, Pollock N, Mias E, McAleer S, Kelly S, Brown F, et al. Eccentric hamstring strength in elite track and field athletes on the British Athletics world class performance program. Phys Ther Sport. 2020:43:217-23.

27. Hegyi A, Lahti J, Giacomo J-P, Gerus P, Cronin NJ, Morin J-B. Impact of hip flexion angle on unilateral and bilateral Nordic hamstring exercise torque and high-density electromyography activity. J Orthop Sport Phys Ther. 2019; 49:584-92.

28. Opar DA, Williams MD, Timmins RG, Hickey J, Duhig SJ, Shield AJ. Eccentric hamstring strength and hamstring injury risk in Australian footballers. Med Sci Sports Exerc. 2015;47:857-65.
29. Bourne MN, Opar DA, Williams MD, Shield AJ. Eccentric knee flexor strength and risk of hamstring injuries in rugby union. Am J Sports Med. 2015;43: 2663-70.

30. Opar DA, Williams MD, Timmins RG, Hickey J, Duhig SJ, Shield AJ. The effect of previous hamstring strain injuries on the change in eccentric hamstring strength during preseason training in elite Australian footballers. Am J Sports Med. 2015;43:377-84.

31. Timmins RG, Bourne MN, Shield AJ, Williams MD, Lorenzen C, Opar DA. Short biceps femoris fascicles and eccentric knee flexor weakness increase the risk of hamstring injury in elite football (soccer): a prospective cohort study. Br J Sports Med. 2016;50:1524-35.

32. van Dyk N, Bahr R, Burnett AF, Whiteley R, Bakken A, Mosler A, et al. A comprehensive strength testing protocol offers no clinical value in predicting risk of hamstring injury: a prospective cohort study of 413 professional football players. Br J Sports Med. 2017;51:1695-702.

33. Chalker WJ, Shield AJ, Opar DA, Rathbone EN, Keogh JWL. Effect of acute augmented feedback on between limb asymmetries and eccentric knee flexor strength during the Nordic hamstring exercise. PeerJ. 2018;6:e4972

34. Isik A, Unlu G, Gozubuyuk OB, Aslanyurek T, Bereceli C. The relationship between previous lower extremity injury, body weight and bilateral eccentric hamstring strength imbalance in young soccer players. Montenegrin J Sport Sci Med. 2018;7:23-8.

35. Franchi MV, Ellenberger L, Javet M, Bruhin B, Romann M, Frey WO, Spörri J. Maximal eccentric hamstrings strength in competitive alpine skiers: crosssectional observations from youth to elite level. Front Physiol. 2019;10:88.

36. Thiese MS. Observational and interventional study design types; an overview. Biochem Med. 2014;24:199-210.

37. Wulf $\mathrm{G}$, Shea $\mathrm{CH}$. Principles derived from the study of simple skills do not generalize to complex skill learning. Psychon Bull Rev. 2002;9:185-211.

38. Magill R, Anderson D. Motor learning and control: concepts and applications. 11th ed. New York City: McGraw-Hill Higher Education; 2016.

39. Currell K, Jeukendrup AE. Validity, reliability and sensitivity of measures of sporting performance. Sport Med. 2008;38:297-316.

40. Claudino JG, Mezêncio B, Soncin R, Ferreira JC, Valadão PF, Takao PP, et al. Development of an individualized familiarization method for vertical jumps. Rev Bras Med Esporte. 2013;19:359-62.

41. Bonnette S, Dicesare CA, Kiefer AW, Riley MA, Foss KDB, Thomas S, et al. A technical report on the development of a real-time visual biofeedback system to optimize motor learning and movement deficit correction. J Sport Sci Med. 2020;19:84-94.

42. Myer GD, Stroube BW, Dicesare CA, Brent JL, Ford KR, Heidt RS, et al. Augmented feedback supports skill transfer and reduces high-risk injury landing mechanics: a double-blind, randomized controlled laboratory study. Am J Sports Med. 2013;41:669-77.

43. Croisier JL, Ganteaume S, Binet J, Genty M, Ferret JM. Strength imbalances and prevention of hamstring injury in professional soccer players: a prospective study. Am J Sports Med. 2008;36:1469-75.

44. van Dyk N, Bahr R, Whiteley R, Tol JL, Kumar BD, Hamilton B, Farooq A, Witvrouw E. Hamstring and quadriceps isokinetic strength deficits are weak risk factors for hamstring strain injuries: a 4-year cohort study. Am J Sports Med. 2016:44:1789-95.

45. Jakobi JM, Chilibeck PD. Bilateral and unilateral contractions: possible differences in maximal voluntary force. Can J Appl Physiol. 2001;26:12-33.

46. Zemski AJ, Slater GJ, Broad EM. Body composition characteristics of elite Australian rugby union athletes according to playing position and ethnicity. J Sports Sci. 2015;33:970-8.

47. Bilsborough JC, Greenway KG, Opar DA, Livingstone SG, Cordy JT, Bird SR, et al. Comparison of anthropometry, upper-body strength, and lower-body power characteristics in different levels of Australian Football Players. J Strength Cond Res. 2015;29:826-34.

48. Grant D, David P, Sue H. Applied physiology and game analysis of Rugby Union. Sport Med. 2003:33:973-91.

49. Orchard JW, Seward H, Orchard JJ. Results of 2 decades of injury surveillance and public release of data in the Australian Football League. Am J Sports Med. 2013:41:734-41.

50. Green B, Bourne MN, van Dyk N, Pizzari T. Recalibrating the risk of hamstring strain injury (HSI): a 2020 systematic review and meta-analysis of risk factors for index and recurrent hamstring strain injury in sport. Br J Sports Med. 2020;54:1081-8. 
51. Kenneally-Dabrowski CJB, Brown NAT, Lai AKM, Perriman D, Spratford W, Serpell BG. Late swing or early stance? A narrative review of hamstring injury mechanisms during high-speed running. Scand J Med Sci Sport. 2019; 29:1083-91.

52. Chumanov ES, Schache AG, Heiderscheit BC, Thelen DG. Hamstrings are most susceptible to injury during the late swing phase of sprinting. $\mathrm{Br} J$ Sports Med. 2012;46(2):90.

53. Schache AG, Dorn TW, Blanch PD, Brown NAT, Pandy MG. Mechanics of the human hamstring muscles during sprinting. Med Sci Sports Exerc. 2012;44: 647-58.

54. Schache AG, Dorn TW, Wrigley TV, Brown NATT, Pandy MG. Stretch and activation of the human biarticular hamstrings across a range of running speeds. Eur J Appl Physiol. 2013;113:2813-28.

55. Schimitt B, Tyler T, McHugh M. Hamstring injury rehabilitation and prevention of reinjury using lengthened state eccentric training: a new concept. J Sci Med Sport. 2012;7:333-41.

56. Novacheck TF. The biomechanics of running. Gait Posture. 1998;7:77-95.

57. Mann RA, Hagy J. Biomechanics of walking, running, and sprinting. Am J Sports Med. 1980;8:345-50

58. Schache AG, Dorn TW, Williams GP, Brown NAT, Pandy MG. Lower-limb muscular strategies for increasing running speed. J Orthop Sports Phys Ther. 2014;44:813-24

59. Orchard JW. Hamstrings are most susceptible to injury during the early stance phase of sprinting. Br J Sports Med. 2012;46:88-9.

60. Kyröläinen $H$, Avela J, Komi PV. Changes in muscle activity with increasing running speed. J Sports Sci. 2005;23:1101-9.

61. Askling C, Saartok T, Thorstensson A. Type of acute hamstring strain affects flexibility, strength, and time to return to pre-injury level. Br J Sports Med. 2006:40:40-4.

62. Wiesinger H-P, Gressenbauer C, Kosters A, Scharinger M, Muller E. Device and method matter: a critical evaluation of eccentric hamstring muscle strength assessments. Scand J Med Sci Sports. 2020;30:217-26.

63. Hegyi A, Gonçalves BAM, Finni T, Cronin NJ. Individual region- and musclespecific hamstring activity at different running speeds. Med Sci Sports Exerc. 2019:51:2274-85

64. Hegyi A, Péter A, Finni T, Cronin NJ. Region-dependent hamstrings activity in Nordic hamstring exercise and stiff-leg deadlift defined with high-density electromyography. Scand J Med Sci Sport. 2018;28:992-1000.

65. Opar DA, Williams MD, Shield AJ. Hamstring strain injuries: factors that lead to injury and re-injury. Sport Med. 2012:42:209-26.

66. Al Attar WSA, Soomro N, Sinclair PJ, Pappas E, Sanders RH. Effect of injury prevention programs that include the Nordic hamstring exercise on hamstring injury rates in soccer players: a systematic review and metaanalysis. Sport Med. 2017;47:907-16.

67. Petersen J, Thorborg K, Nielsen MB, Budtz-Jørgensen E, Hölmich P. Preventive effect of eccentric training on acute hamstring injuries in men's soccer: a cluster-randomized controlled trial. Am J Sports Med. 2011;39: 2296-303.

68. Van Dyk N, Behan FP, Whiteley R. Including the Nordic hamstring exercise in injury prevention programmes halves the rate of hamstring injuries: a systematic review and meta-analysis of 8459 athletes. Br J Sports Med. 2019; 53:1362-70.

69. Van Der Horst N, Smits DW, Petersen J, Goedhart EA, Backx FJG. The preventive effect of the nordic hamstring exercise on hamstring injuries in amateur soccer players: a randomized controlled trial. Am J Sports Med. 2015;43:1316-23.

70. Freckleton G, Pizzari T. Risk factors for hamstring muscle strain injury in sport: a systematic review and meta-analysis. Br J Sports Med. 2013;47:351-8.

71. Bittencourt NFN, Meeuwisse WH, Mendonça LD, Nettel-Aguirre A, Ocarino JM, Fonseca ST. Complex systems approach for sports injuries: moving from risk factor identification to injury pattern recognition - narrative review and new concept. Br J Sports Med. 2016;50:1309-14.

72. Bourne MN, Timmins RG, Opar DA, Pizzari T, Ruddy JD, Sims C, et al. An evidence-based framework for strengthening exercises to prevent hamstring injury. Sport Med. 2018;48:251-67.

73. Hunter JP, Marshall RN, McNair PJ. Relationships between ground reaction force impulse and kinematics of sprint-running acceleration. J Appl Biomech. 2005;21:31-43.

74. Kawamori N, Nosaka K, Newton RU. Relationships between ground reaction impulse and sprint acceleration performance in team sport athletes. J Strength Cond Res. 2013;27:568-73.
75. Morin JB, Gimenez $P$, Edouard $P$, Arnal $P$, Jiménez-Reyes $P$, Samozino $P$, et al. Sprint acceleration mechanics: the major role of hamstrings in horizontal force production. Front Physiol. 2015;6:1-14.

76. Ishøi L, Aagaard P, Nielsen MF, Thornton KB, Krommes KK, Hölmich P, Thorborg K. The influence of hamstring muscle peak torque and rate of torque development for sprinting performance in football players: a crosssectional study. Int J Sports Physiol Perform. 2019;14:665-73.

77. Romero-Franco N, Jiménez-Reyes P, Castaño-Zambudio A, Capelo-Ramírez F, Rodríguez-Juan JJ, González-Hernández J, Toscano-Bendala FJ, CuadradoPeñafiel V, Balsalobre-Fernández C. Sprint performance and mechanical outputs computed with an iPhone app: comparison with existing reference methods. Eur J Sport Sci. 2017;17:386-92.

78. Mendiguchia J, Edouard P, Samozino P, Brughelli M, Cross M, Ross A, Gill N, Morin JB. Field monitoring of sprinting power-force-velocity profile before, during and after hamstring injury: two case reports. J Sports Sci. 2016;34: 535-41.

79. Nagahara R, Mizutani M, Matsuo A, Kanehisa H, Fukunaga T. Association of sprint performance with ground reaction forces during acceleration and maximal speed phases in a single sprint. J Appl Biomech. 2018:34:104-10.

80. Wdowski MM, Gittoes MJR. First-stance phase force contributions to acceleration sprint performance in semi-professional soccer players. Eur J Sport Sci. 2020;20:366-74.

81. Loturco I, D'Angelo RA, Fernandes $V$, et al. Relationship between sprint ability and loaded/unloaded jump tests in elite sprinters. J Strength Cond Res. 2015;29(3):758-64

82. McFarland I, Dawes JJ, Elder C, Lockie R. Relationship of two vertical jumping tests to sprint and change of direction speed among male and female collegiate soccer players. Sports. 2016;4:11.

83. Asadi A. Relationship between jumping ability, agility and sprint performance of elite young basketball players: a field-test approach. Brazilian J Kinanthropometry Hum Perform. 2016;18:177-86.

84. Claudino JG, Cronin J, Mezêncio B, McMaster DT, McGuigan M, Tricoli V, et al. The countermovement jump to monitor neuromuscular status: a meta-analysis. J Sci Med Sport. 2017;20:397-402.

85. Claudino JG, Cronin JB, Amadio AC, Serrão JC. How can the training load be adjusted individually in athletes with an applied statistical approach? J Athl Enhanc. 2016;5:6.

\section{Publisher's Note}

Springer Nature remains neutral with regard to jurisdictional claims in published maps and institutional affiliations.

\section{Submit your manuscript to a SpringerOpen ${ }^{\circ}$ journal and benefit from:}

- Convenient online submission

- Rigorous peer review

- Open access: articles freely available online

- High visibility within the field

- Retaining the copyright to your article

Submit your next manuscript at $>$ springeropen.com 